ISSN 1112-9867

http://www.jfas.info

\title{
USE OF XPS THERMAL INSULATOR BOARDS IN DESIGN OF EDUCATIONAL SPACES
}

\author{
F. Davari Dolatabadi ${ }^{1}$ and A. Emamianfar ${ }^{2}$ \\ ${ }^{1}$ Master of Science student in Architectural Technology, Jolfa Branch, Islamic Azad \\ University, Jolfa, Iran \\ ${ }^{2}$ Faculty member, Dolatabad Branch, Islamic Azad University, Dolatabad, Iran
}

Published online: 15 May 2016

\begin{abstract}
This research refers to case study, Haghpanah girls' primary school that is of the standard schools designed and implemented by Isfahan Province Schools Renovation Organization. It deals to the importance and creation of an operational method for applying modern materials such as XPS thermal insulator in architectural design and its effect on educational spaces in section of primary school and how to design. It also deals to its effect and advantages on interior spaces that will help educational optimization significantly. Perhaps some believe that the implementation of thermal insulation of the building increases construction costs. However, we note that the implementation of thermal insulation not only saves energy consumption but also has a significant role in consumption of wasted heating and cooling energy of educational spaces. For example, the position of mentioned school is on the ground floor (pilot) and with external walls around the building. As it is obvious, the building floor and three sides of its perimeter are a part of the external shell (in contact with the outside perimeter). Cooling and heating of such a building requires spending high costs to provide equipment with high capacities. Heating and cooling equipment capacity becomes smaller than half after proper implementation of thermal insulation.
\end{abstract}

Author Correspondence, e-mail: Tarahan1400@yahoo.com

doi: http://dx.doi.org/10.4314/jfas.v8i3s.248 
As air conditioning equipment becomes small, implementation of optimization not only becomes free but also reduces the overall cost of construction.

Keywords: School, modern materials, Building and Housing Research Center, XPS boards

\section{INTRODUCTION}

Building insulation is one important ways to reduce energy consumption and consequently reduce costs in building. Hence, we decided to investigate the properties of XPS thermal insulator boards to be placed in the best possible conditions in terms of correct and complete retention or transfer of energy to the intended places by considering preparations.

Proper implementation of these factors and its appropriate insulation can have a significant role in reducing waste of energy and costs. It itself leads to advance in technology and the necessity of constructing lighter buildings. Consequently, the walls' thickness is reduced to a possible minimum. The escape of heat from the external shell of the building has been posed after it.

So, thermal conductivity coefficient of the complex has been reduced significantly by placing thermal insulation in the buildings' shell collection in order to reduce the cost of creation of heat and cold. This will be approved by the Building and Housing Research Center.

\section{CONCEPTS SCHOOL}

"School" is one of the words with history in Iran, which was used as equivalent for "Islamic seminary" with its today's meaning before the establishment of polytechnic institution (1268 $\mathrm{AH} / 1851 \mathrm{AD})$. It was a place attached to the mosque as a religious institution to teach courses related to the laws and religious law and with legitimation system, a particular part that has being applied by "teacher" and then "priest" and "jurisconsult" for theologian.

But more diverse and different educational content was formulated later in the same word for space separated from the mosque, but with the same name of school compared to what was offering in the "old schools" or "old-fashioned primary schools". This separation regardless of its spatial dimension, as well as content of courses was from a foundation with a different legitimizing system and hierarchy. 


\section{BUILDING AND HOUSING RESEARCH CENTER}

The need for housing had been one of the main necessaries of human life in all periods. Having house appropriate with need has been also considered as the right of every individual and Iranian family in Article 31 of the Islamic Republic of Iran's constitution. The transition from traditional production method to industrial production method is an undeniable principle by citing to the perspective of development in horizon of 1404 as well as in line with the production of high quality and cheap house in which traditional methods of construction are not optimal.

Leading this affair has been granted to the Building and Housing Research Center according to the law. So that it confirms modern constructional technologies according to the technical and legal indicator and to promote it.

\section{XPS THERMAL INSULATOR}

XPS thermal insulator boards are extruded polystyrene foams with nested and compressed texture and free of hole. It greatly helps to the resistance of this foam against the moisture penetration.

These boards are used in insulation of floor, roof and walls of residential and industrial buildings.

\section{RESEARCH METHODOLOGY}

This research methodology has been expressed descriptive - analytical based on information available at the place of Isfahan Renovation Organization and the province schools and Building and Housing Research. It had been also on the way of thermal insulators' effect on design of educational spaces and the way of effectiveness of XPS thermal insulators in hot and dry climates such as Haghpanah School located in Isfahan province

XPS thermal insulator has been compared with few samples of variety of thermal insulator about cases such as compressive strength, thermal conductivity coefficient, water absorption, and density in this article based on the provided information.

\section{Case study of Isfahan Haghpanah Girls' Primary School}


One of the schools of Isfahan city known as colored pencil school is an example of smart schools in Iran. Its designers have tried to give succulence and joy to its students by applying color in architectural and interior space design of it and it has an effect in the process of their learning lesson.

This school has been located in District 5 of Isfahan. It has an infrastructure of 1,700 square meters on an area of 2900 square meters with 12 classrooms (grades one to six), experimental class, library, conference hall, and computer room. This school is considered of the smart schools.

All classrooms are equipped with electronic equipment and smart board. Of course, this school is considered of Qur'an specialized schools. Interesting points of architectural design in the design of this space have been done as follows.

- Applying simple and understandable volumes for child and avoidance of any complexity in spatial organization

- Use of color in such a way that represents the role and personality in the external facade and leads to creation of a sense of relaxation along with vitality and freshness inside

- Visual influence in the body associated with the city in order to connect the city and the school and create movement and mobility in urban body

- And reduction of the sense of being surrounded inside the building.
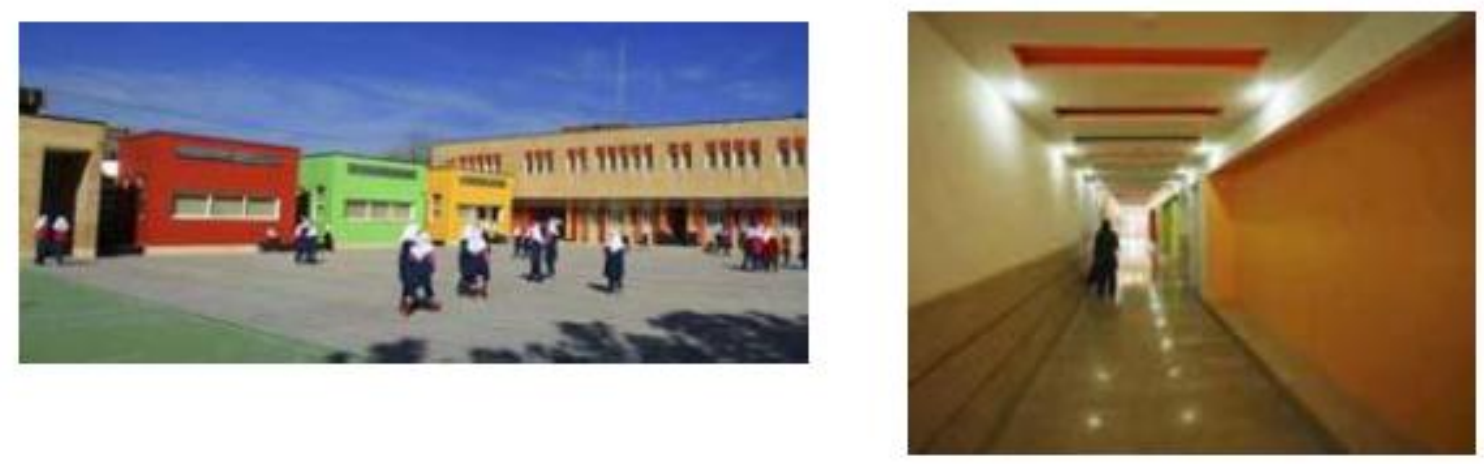

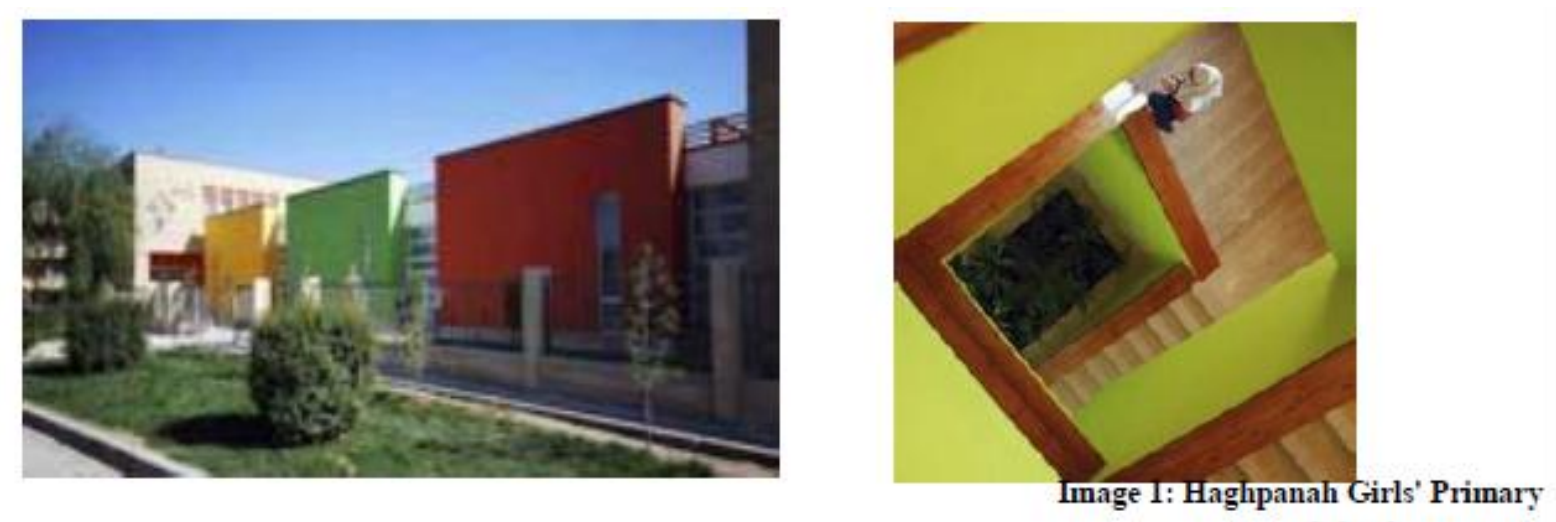
School
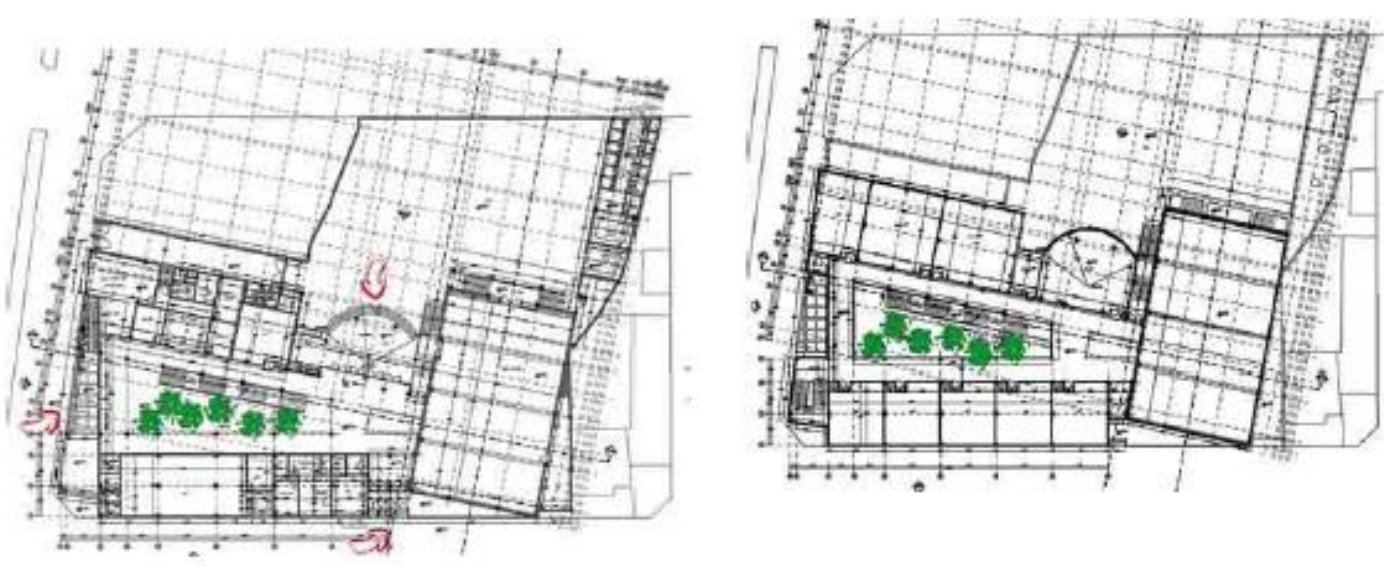

Inage 3: Map of ground floor of Haghpanah Girls' Primary School

Inage 2: Map of first floor of Haghpanah Girls' Primary School 


\begin{tabular}{|c|c|c|c|c|c|c|c|c|}
\hline \multicolumn{9}{|c|}{ Joinery Table } \\
\hline \multirow{2}{*}{\multicolumn{2}{|c|}{ Dropped ceiling }} & \multirow{3}{*}{$\begin{array}{c}\text { Roof } \\
\text { Quality }\end{array}$} & \multicolumn{2}{|c|}{ Wall } & \multirow{3}{*}{$\begin{array}{l}\text { Floor } \\
\text { Quality }\end{array}$} & \multirow[t]{3}{*}{ Space name } & \multirow{3}{*}{$\begin{array}{l}\mathrm{F} \\
1 \\
0 \\
0\end{array}$} & \multirow{3}{*}{$\begin{array}{l}\mathrm{R} \\
0 \\
w\end{array}$} \\
\hline & & & \multirow{2}{*}{$\frac{\text { Cornice }}{\text { Quality }}$} & \multirow{2}{*}{$\frac{\text { Body }}{\text { Quality }}$} & & & & \\
\hline $\begin{array}{c}\mathrm{Col} \\
\ldots\end{array}$ & Quality & & & & & & & \\
\hline & & & & & & & & \\
\hline White & Plastery panel & Plester and & 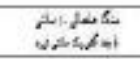 & 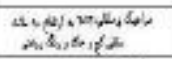 & Behsangan & Corridor lobby & Gr & $\frac{1}{1}$ \\
\hline 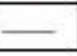 & $\longrightarrow$ & Plaster and & 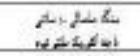 & 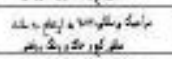 & Grenitic & Cassroom & i & 4 \\
\hline White & Plastery & Plaster and & Alidabe & 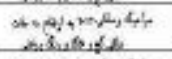 & Behsangson & Assistant teschers rest & n & \\
\hline white & Plostery & Plaster and & 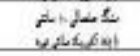 & 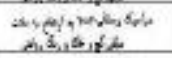 & Behsangan & Deportmentsi and princips: & f & i \\
\hline 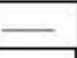 & - & Plaster and & $\longrightarrow$ & 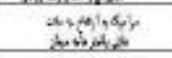 & Iranian mosaic & Powerhouse & or & 8 \\
\hline whit & $\mu \mathrm{co}$ & 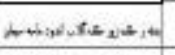 & $\longrightarrow$ & misnerd & 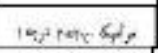 & Teschers' senvice & pil & 7 \\
\hline Whit & pit & 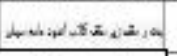 & $\longrightarrow$ & 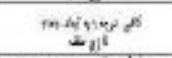 & 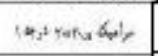 & Butiers pontry & on & V \\
\hline- & & Plaster and & 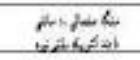 & 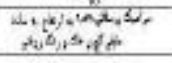 & 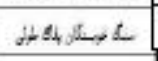 & Connecting stairs & & $\hat{A}$ \\
\hline 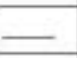 & & Plaster and soil & 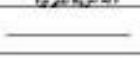 & $\operatorname{mintar}_{4}$ & $10 x m_{n}(4)$ & Student service & & 3 \\
\hline - & & Plester and & $\longrightarrow$ & mownopd & 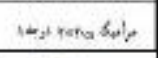 & Orinking fountain & & i. \\
\hline 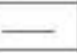 & & Plaster and & hilidak & wealdexily & Behsangan & Computer room & & 17 \\
\hline 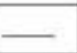 & $\longrightarrow$ & Paster and & 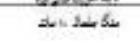 & 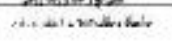 & $\ldots$ & Warehouse & & ir \\
\hline White & Plistery ponel & Plaster and & 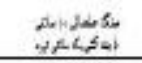 & 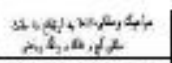 & Behsargan & Corridor lobby & Fi & if \\
\hline 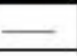 & & Plaster and & 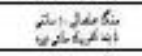 & $200,1, n, 4,45$ & Granitic design & Clsssroom & $\begin{array}{c}r 3 \\
t\end{array}$ & Lis \\
\hline- & - & Plaster and & 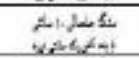 & 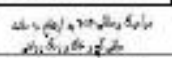 & wat $x^{2}, 4$ & Labratory & $\begin{array}{l}\pi \\
0\end{array}$ & \\
\hline & & Plaster and soil & 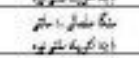 & 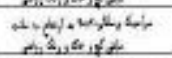 & 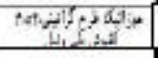 & Librory & $\begin{array}{l}0 \\
0\end{array}$ & 17 \\
\hline White & Plastery & Flaster and & $\begin{array}{l}x+2 \leq 6 \\
30<x-1\end{array}$ & 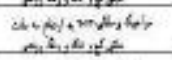 & Behsargan & Training room & $\begin{array}{l}r \\
p i\end{array}$ & iv \\
\hline White & Plastery ponel & Plaster and & 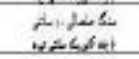 & $a^{2} x^{2}, 4 y^{1}$ & 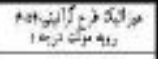 & Chapel & 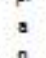 & in \\
\hline whit & $p o c$ & 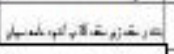 & $\longrightarrow$ & $m_{t i t} w^{2}$ & 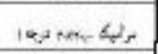 & TRAblution place & $n$ & 11 \\
\hline- & & Plaster and soil & 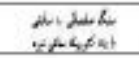 & 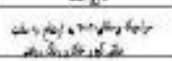 & 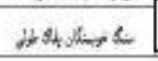 & Connecting stsirs & & r. \\
\hline
\end{tabular}

\section{XPS THERMAL INSULATOR BOARDS}

XPS thermal insulator boards are extruded polystyrene foams with nested and compressed texture and free of hole. It greatly helps to the resistance of this foam against the moisture penetration.

These boards are used in insulation of floor, roof and walls of residential and industrial buildings.

Their compressive strength is high because there is no bubble in their structure. Their water absorption is also low and is only $0.2 \%$. Also, there is no water penetration in them through the capillary. These foams can be easily cut with a saw or knife and hot wire is not needed. They are easily fixed in their place by glue and / or screw. 
Their thermal conductivity coefficient is also between 0.014 and 0.022 . This product has been evaluated in Building and Housing Research Center and its usage in the scope of the provided occasions is allowed. (Ministry of Housing and Urbanism, 2009)

XPS building insulator is the new generation of building insulator that has unique features. None of the usual buildings insulators have these features. The extruded polystyrene insulator board that is briefly known as XPS is an insulator board that is widely used in building and industry. This manufacture is obtained by mixing ordinary polystyrene (GPPS) with Foaming Agents during the extrusion process. (Www.poosheshbtj.com, 2015)
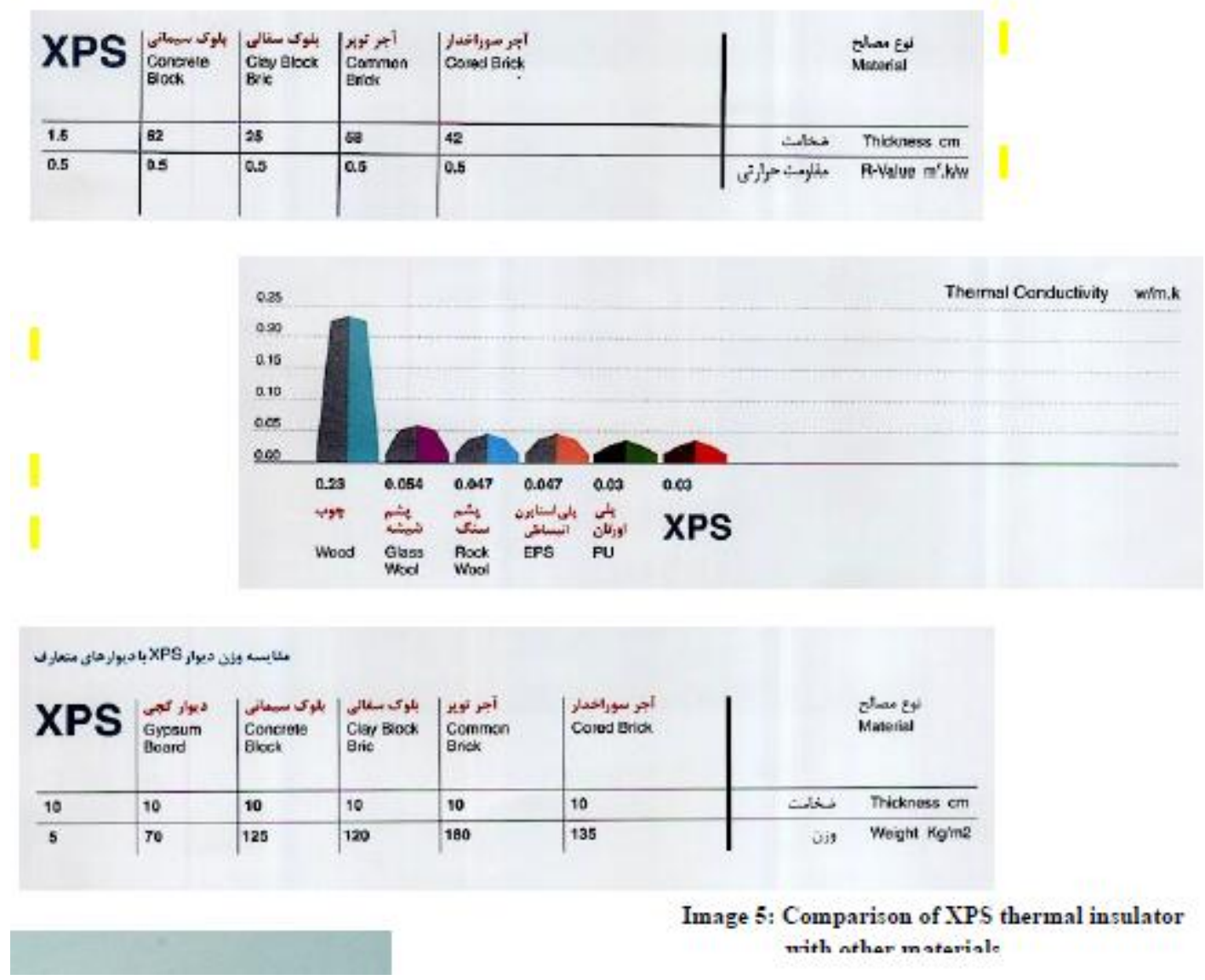

The produced building insulator is free of any destructive gases for environment like CFC that their usage has been prohibited according to the legislated laws of Montreal Protocol. XPS building insulator has been substituted with rock wool, fiberglass and EPS insulator board (known as EPS in our country) for building insulation because of its own features in many cases. 


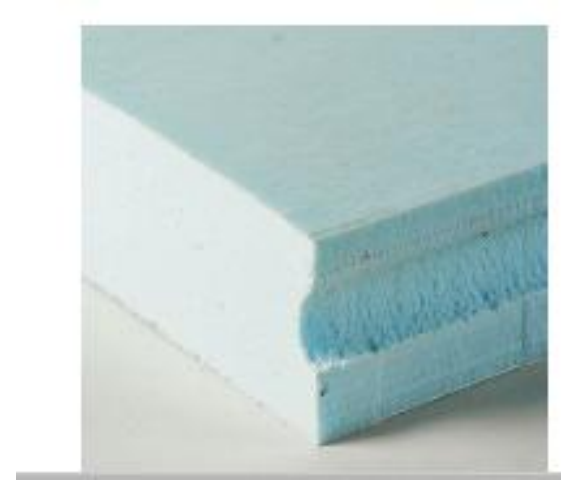

In addition to the insulation features, the surfaces created after installing XPS building insulator have a special capability for the use of traditional materials. (Www.poosheshbtj.com, 2015)

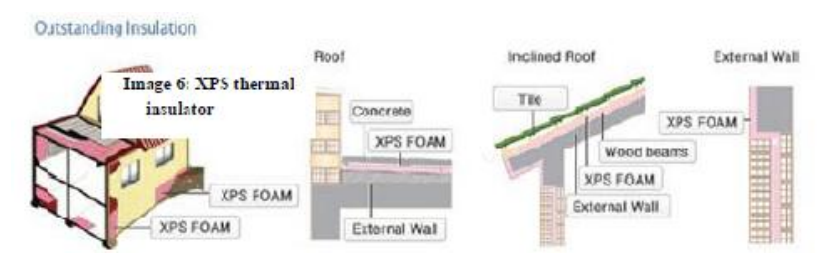

\section{Some of the usages of XPS building insulator in building and industry:}

The width is $60-90-120$. The length is produced infinite and the thickness 12 to $2 \mathrm{~cm}$. The special weight is produced 38 to 40 kilograms per square meter.

1. Construction of insulator wall

2. Roof insulation

3. Insulation of external walls / use as insulator in brick and stony walls

4. Floor insulation

5. Insulation of walls, roof and floor refrigerating rooms

6. Insulation of surfaces to prevent freeze of buildings, streets and rail lines

7. Insulation of foundation walls

8. Use as the core of sandwich panel insulator

XPS insulator wall 
The use of Dry Walls and non-load-bearing walls is expanding in the world. This system uses a galvanized light metal skeleton to implement wall. Its two sides are covered with appropriate boards.

Various covering boards are applied such as gypsum board, gypsum cement and XPS building insulator. The produced XPS building insulator boards have many advantages compared to similar systems. These advantages are as follows:

* High speed and accuracy in execution - significant decrease in project execution time

* Very desired insulator against heat and noise

* Appropriate price

* Low waste

* High safety because of low weight

* Reduction of construction cost of foundation and structure because of reduction of dead load and thus immunization against earthquake *because of* lightness

* Architectural flexibility

* A significant reduction of noise and pollutions in the project environment

* Standard resistance against fire

* Fulfilling the occasions of Subject19

* Implementation of various coating materials such as plaster and cement on it will be possible

XPS building insulator is more suitable compared to the other insulators for working on metal skeleton because of its extraordinary feature against water absorption (www.poosheshbtj.com, 2015) 


\begin{tabular}{|c|c|}
\hline XPS & Product type \\
\hline $12010-2500 \mathrm{~mm}$ & Length \\
\hline $600, \infty 60,1200) \mathrm{mm}$ & Width \\
\hline $25.100 \mathrm{~mm}$ & Thickness \\
\hline 32-35 tgen' & Density \\
\hline 0.029 Whak & Thermal penetration at \\
\hline 0.032 Wink & $\begin{array}{l}\text { Thermal penetration at } \\
\text { average tempersture of } 24^{\circ} \mathrm{C}\end{array}$ \\
\hline $300 \mathrm{KPa}$ & Compressive strength \\
\hline $100.200 \%$ & Resistance sgoinst water vapor \\
\hline 0.40 .6 par inch & Water vapor permes bility \\
\hline $0.2 \%$ by Val. & Water sbsorption \\
\hline Does not have & Codillarv Denetration \\
\hline $70 \times 10^{6} e^{-t}$ & Coefficient of expansion and \\
\hline BI & Resistsnce acainst fire \\
\hline
\end{tabular}

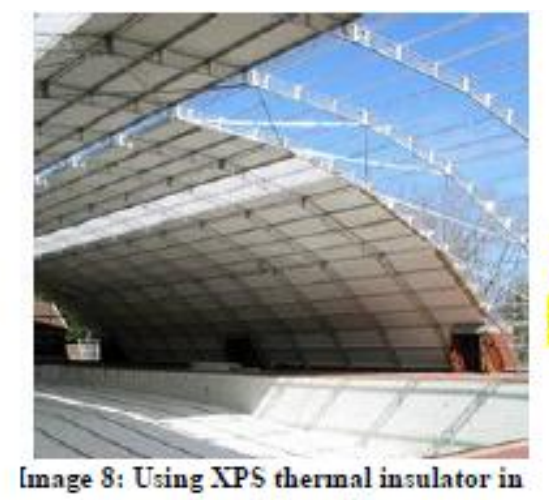

nishao aciline

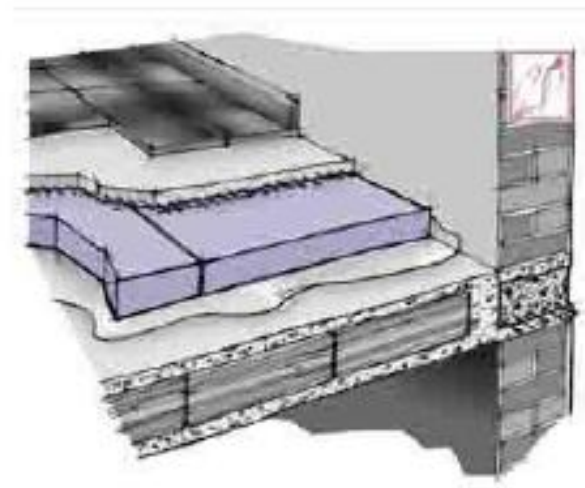

Inage 10: Roof layering in implementation of $\mathrm{Xps}$ thermal insulator

\section{BUILDING INSULATOR IMPLEMENTATION METHOD:}

\section{Wall with XPS building insulator boards on both sides:}

At the first stage, U-shaped runners are installed to the floor and the roof and sides by nail gun and / or screw and dowel according to the Figure. at the next stage, stands and structures of equipment installation are installed at maximum distances of $60 \mathrm{~cm}$ by steel screws with drill head to the runners by regarding to the location of door and windows, as well as the location of installation of cabinet, radiator, fan coil, wash-stand, LCD and so on. 
Then water, electricity and sewage tubes are inserted in the space between the stands according to the map of installation. At the next stage, boards with a thickness of 2 to $3 \mathrm{~cm}$ screw up XPS into the two surfaces of wall by screws with drill head and special umbilical galvanized washers to the structure.

The XPS surface is lined by a cement special for XPS after this stage. As it has been shown in the Figure, the wall will be completely ready after this stage for friction and / or installation of all traditional and modern materials that are specified based on the architectural details. In addition, polyurethane foam is used to fix installation tubes to the wall. (Golabchi, Mzahryan, 2009)

\section{Wall with XPS boards in the middle:}

All the stages of first method are implemented in this method. The difference is that the XPS boards will be placed inside it instead of being installed on both sides when installing runners and stands. (Golabchi, Mzahryan, 2009)

\section{TECHNICAL SPECIFICATIONS OF XPS}

Synergy xps thermal insulator has been produced from extruded polystyrene with high thermal and compressive strength for thermal insulation. The production process is based on materials melting technology, continuous mixing and injection and compression in high temperature to produce hard insulator boards.

This method unlike other production methods that cause cavity, pore, and capillary tubes in the insulator provides a uniform texture with closed and impermeable cells. Very low thermal conductivity coefficient and high resistance against moisture penetration and pressure compared to other insulators are of the unique features of this type of insulator.

\begin{tabular}{|c|c|c|c|c|c|}
\hline $\begin{array}{l}\text { Sim XPS ye } 2 y \\
\text { Synergy XPS board }\end{array}$ & Rockwool & Phenolic & EPS & ro & Insulation type \\
\hline $200-700$ & $100-150$ & $80-200$ & $100-180$ & $100-160$ & $\begin{array}{l}\text { Compressive strength } \\
\text { (KPa) }\end{array}$ \\
\hline $0.025-0.032$ & $0.034-0.040$ & $0.022 \cdot 0.028$ & $0.036 \cdot 0.039$ & $0.022 \cdot 0.028$ & $\begin{array}{l}\text { Thermal conductivity } \\
(\text { Wim.K) }\end{array}$ \\
\hline 0.0 .5 & $2.5 \cdot 10$ & $0.2 \cdot 0.7$ & 0.5 & $2-5$ & $\begin{array}{l}\text { Water absorption } \\
\text { (NWVol). }\end{array}$ \\
\hline $30 \cdot 50$ & $70-150$ & $35 \cdot 55$ & $10-25$ & $36 \cdot 50$ & $\begin{array}{l}\text { Density } \\
\left(\mathrm{kg} / \mathrm{m}^{2}\right)^{-}\end{array}$ \\
\hline
\end{tabular}

Image 11: Comparison of Xps thermal insulator

boards with other thermal insulator 


\section{COMPARISON OF THERMAL INSULATORS}

XPS building insulator is an insulator with very high level of insulator. Thermal conductivity coefficient of the materials and their thermal resistance has a particular importance in the use of insulators. So that the materials or composed system that effectively reduce transfer of heat from an environment to another environment is called usable thermal insulator in the building in the Book of Building National Subject 19.

\begin{tabular}{|c|c|c|}
\hline Thickness & \multicolumn{2}{|c|}{ Rilaciantum } \\
R.Value \\
\hline (mm) & $\pi^{2}$. F.h/BTU & $\mathrm{m}^{2} . \mathrm{kN}$ \\
\hline 25 & 4.73 & 0.83 \\
\hline 40 & 7.57 & 1.33 \\
\hline 50 & 9.46 & 1.66 \\
\hline 60 & 11.35 & 2 \\
\hline 80 & 15.13 & 2.67 \\
\hline
\end{tabular}

That is an insulator that its thermal conductivity is ' $\mathrm{Y}$ less than or equal to $0.065 \mathrm{~W} / \mathrm{M} . \mathrm{K}$ and its thermal resistance is equal to or greater than $0.5 \mathrm{M} . \mathrm{K} / \mathrm{W}$. Thermal resistance increases when ' $Y$ reduces based on heat formula. So that $1.5 \mathrm{~cm}$ thickness is required to create thermal resistance of $\mathrm{R}=0.5$ of XPS board according to the following table. Clay block with a thickness of $25 \mathrm{~cm}$ or cored brick with a thickness of $42 \mathrm{~cm}$ thick is required to achieve to the same resistance. (Www.poosheshbtj.com, 2015)

\begin{tabular}{|c|c|c|c|}
\hline Reference Method & Test result & Specificity of the test & Row \\
\hline National standard 7118 & 32.97 & Density (km per sq.m) & 1 \\
\hline National standard 8261 & 0.0302 & Coefficient of thermal conductivity (watt per meter & 2 \\
\hline National standard 8261 & 2.066 & Thermal resistance (Kelvin square meter per watt meter) & 3 \\
\hline National standard 7300 & 0.048 & Water absorbtion & 4 \\
\hline National standard 7299 & Balance 150 & Resistance coefficient against water vapor penetration & 5 \\
\hline National standard 7299 & 163.9 & Water vapor transfer rate $\left(\mathrm{mg} \mathrm{m}^{2} \mathrm{~h}\right)$ & 6 \\
\hline National standard 7299 & 0.00407 & Water vapor vermeabilitv (me per $\mathrm{m} . \mathrm{h} . \mathrm{Pal}$ & 7 \\
\hline National standard 7299 & 204.00 & Coefficient of penetration resistance against water vabor & 8 \\
\hline
\end{tabular}

Image 13: Table of Building and Housing Research Center test results on Xps thermal insulator 


\section{CONCLUSION}

Any use of the thermal insulator has not been considered in this case sample that has been presented. Diversity of color and form had been considered mostly. However, XPS boards have been evaluated with other thermal insulators in cases of compressive strength, thermal conductivity coefficient, water absorption, and density. All the referred cases have the best efficiency.

XPS boards have a very low weight and very low water absorption. Therefore, this product can be highly used in schools and building-constructions and even also in the industry and take a great step in saving energy. Ultimately, that building industrial production is not a slogan but is an important need. We should reach to the industry self-esteem for achieving to the operation stage.

Serious support from industrial production should be done and the public economy should give its place to the free economy to realize this affair. It means a place where the private sector can have risk and maneuver power with peace of mind and without concern for the risk of bankruptcy.

It is also necessary to study about choosing the consumer materials to achieve the aforementioned objectives. We should do this work with intelligent vision. Thus, sustainable use for the future generations will be also considered in addition to preventing energy waste.

\section{SOURCES AND REFERENCES}

www.poosheshbtj.com. (2015).

Schools Renovation Organization of Isfahan province. (Undated).

Golabchi, Mzahryan. (2009). Construction of innovative technologies. Tehran: Tehran.

Department of Urban Planning, and. D. (2009). Building new technologies. Tehran.

\section{How to cite this article:}

Davari Dolatabadi F, Emamianfar A.Use of xps thermal insulator boards in design of educational spaces. J. Fundam. Appl. Sci., 2016, 8(3), 1191-1203. 